Originais recebidos em 24/02/2021. Aceito para publicação em 04/05/2021.

Avaliado pelo sistema double blind peer review. Publicado conforme normas da ABNT.

Open acess free available online.

DOI: https://doi.org/10.35700/2359-0599.2022.16.3161

\title{
Turismo em Florianópolis: uma roda de conversa sobre sustentabilidade
}

Fabiana Calçada de Lamare Leite - https://orcid.org/0000-0002-1173-7978 ${ }^{1}$

Risolete Maria Hellmann - https://orcid.org/0000-0001-9426-1444 ${ }^{2}$

\begin{abstract}
RESUMO
A "Roda de Conversa sobre preservação e sustentabilidade no Turismo em Florianópolis" consistiu em uma troca de relatos da experiência da atividade turística entre profissionais Guias de Turismo e Condutores Ambientais. A atividade foi organizada por estudantes do Curso Superior de Tecnologia em Gestão de Turismo do Instituto Federal de Educação, Ciência e Tecnologia de Santa Catarina (IFSC), Câmpus Continente, sob supervisão de uma professora coordenadora. A atividade aconteceu remotamente com a adesão de 65 participantes, sendo $26,2 \%$ da comunidade externa. Como resultado dessa atividade, foi elaborada uma cartilha com as principais ações mencionadas pelos convidados que contribuem para uma atividade turística sustentável e que preserve o meio ambiente e a cultura local.
\end{abstract}

Palavras-chave: roda de conversa; turismo; Florianópolis; preservação; sustentabilidade.

${ }^{1}$ Doutora em Geografia pela Universidade Federal Fluminense, Professora do IFSC, Câmpus FlorianópolisContinente. E-mail: fabianac@ifsc.edu.br

${ }^{2}$ Doutora em Literatura pela Universidade Federal de Santa Catarina, Professora IFSC, Câmpus Florianópolis-Continente. E-mail: risolete.hellmann@ifsc.edu.br 


\title{
Tourism in Florianópolis: conversation about preservation and sustainability
}

\author{
ABSTRACT
}

The debate about preservation and tourism sustainability in Florianópolis consisted in a conversation about experience reports of tourism between Tourism Guides and Nature Guides. The activity was organized by students from the Technology Course in Tourism Management at Institute Federal of Santa Catarina, (IFSC) and a coordinating professor. The activity happened remotely with the participation of 65 participants, $26.2 \%$ from the external community. As a result of this activity, a booklet was created with the main actions mentioned by the guests that contribute to a sustainable tourist activity and that preserve the environment and local the culture.

Keywords: conversation circles; tourism. Florianópolis; preservation; sustainability.

\section{INTRODUÇÃO}

A Organização Mundial do Turismo (OMT) destaca o papel relevante na esfera econômica da atividade turística, uma vez que representa cerca de $10 \%$ do PIB e dos empregos no mundo (OMT, 2020). Assim, é amplamente reconhecida a capacidade que o turismo tem de alterar os sítios físicos e culturais que se tornam territórios da função turística (BURGOS; MERTENS, 2015).

A atividade narrada nesse relato de experiências foi o resultado da atividade final de um projeto selecionado pelo Edital PROEX no 16/2020 - Aluno Extensionista ${ }^{3}$ e foi realizada pela equipe formada por estudantes do Curso Superior de Tecnologia em Gestão de Turismo do IFSC, Câmpus Continente e coordenado pelas autoras deste relato. Destacase que o referido curso superior possui na sua grade curricular, disciplinas relacionadas à extensão universitária, atendendo a meta 12 do Plano Nacional de Educação de 2014, de assegurar no mínimo 10\% (dez por cento) do total de créditos curriculares exigidos para a graduação em programas e projetos de extensão universitária. Com isso, a participação de estudantes nesse projeto contribuiu para a formação de extensionistas.

0 objetivo geral foi promover uma roda de conversa com a temática sobre atividades turísticas sustentáveis que preservem a natureza e a cultura local de

\footnotetext{
30 edital proposto pela Diretoria de Extensão do IFSC e executado por meio da escolha de projetos tem como objetivo apoiar a formação de discentes e servidores(as) do IFSC, assim como da comunidade externa, por meio da realização de um curso de extensão, potencializando os currículos envolvidos visando aumentar a percepção e formas de cooperar/contribuir com o arranjo produtivo local.
} 
Florianópolis. Como objetivos específicos foram traçadas metas com o foco específico nas atividades turísticas relacionadas à preservação da sustentabilidade. São eles: conhecer profissionais, debater e divulgar as ações e conscientizar a comunidade a respeito das ações promovidas por atividades turísticas relacionadas à preservação e a sustentabilidade.

Em reuniões de equipe, foram estabelecidas diretrizes para a organização do evento online e determinação de funções para cada integrante. Entre as tarefas coletivas e individuais estavam: ações de relações externas, como a seleção e convite aos convidados palestrantes e socialização de um roteiro para o evento (elaborado coletivamente); ações de marketing, como elaboração das artes e escolha dos canais para divulgação do evento e inscrição de públicos ouvintes (interno e externo); ações de infraestrutura, como a definição de canal digital e reserva do espaço, controle da frequência/participação dos ouvintes, entre outras atribuições.

A ação foi realizada por meio de uma roda de conversa com quatro convidados profissionais Guias de Turismo, os quais atuam no segmento de natureza e preservação do patrimônio cultural. A pergunta central que norteou o debate foi: De que maneira a atividade turística exercida por vocês contribui para a preservação e sustentabilidade do turismo em Florianópolis?

A escolha do tema Preservação e Sustentabilidade no Turismo teve como pressuposto a relevância da discussão que vem sendo realizada em todo o mundo, tanto por ambientalistas, quanto por gestores de turismo que buscam desenvolver a consciência socioambiental, assim como conciliar a preservação com o crescimento turístico, satisfazendo as necessidades econômicas, ambientais e turísticas.

Essa abordagem e relevância fundamentam-se na relação potencial em que o turismo tem para contribuir, direta ou indiretamente, com os Objetivos do Desenvolvimento Sustentável (ODS) estabelecidos em 2015 pelos países membros das Nações Unidas por meio da Agenda 2030, uma política global para o Desenvolvimento Sustentável que tem como objetivo elevar o desenvolvimento mundial e melhorar a qualidade de vida de todos. Em particular ao turismo, foi relacionado como meta os objetivos referentes ao crescimento econômico inclusivo e sustentável, consumo e produção sustentáveis e uso sustentável de oceanos e recursos marinhos (OMT, 2020).

A divulgação ocorreu pelo perfil pessoal das redes sociais e pelos contatos de WhatsApp dos integrantes da equipe, pela página do Facebook do Câmpus Continente e pelo perfil do Instagram do CST em Gestão de Turismo. ${ }^{4}$

\footnotetext{
4 @gestaoturismo.ifsc
} 
Figura 1 - Arte de divulgação

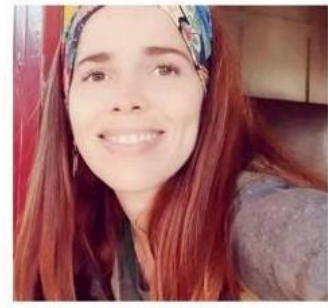

Guia Carol Floripa
Curso Superior de Tecnologia em Gestão de Turismo IFSC Continente convida:

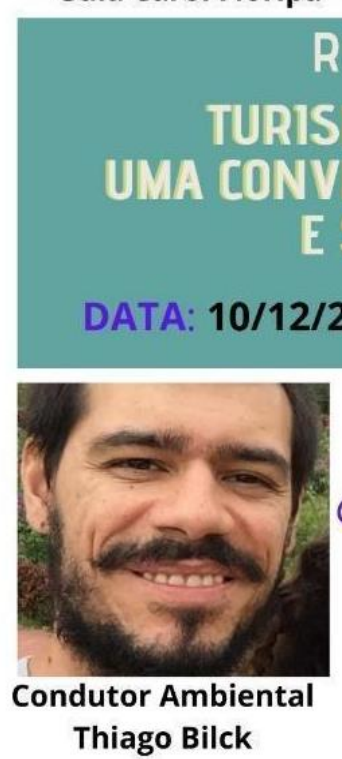

RODA DE CONVERSA:

Guia Luciana Zagonel

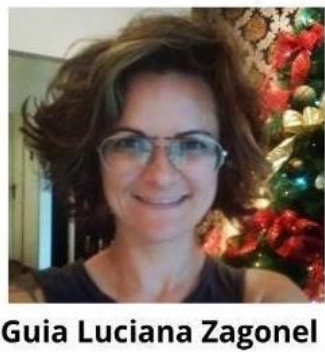

SMO EM FLORIANÓPOLIS:

SUSTENIABILIDADE

ERSA SOBRE PRESERVAÇĀO

Quinta-feira | HORÁRIO: 19h

Fonte: Arte elaborado pela equipe organizadora

As inscrições foram feitas por formulário específico do Google que teve seu link disponibilizado aos interessados e pelos canais de divulgação. Assim, foi possível mensurar o perfil do público participante. Durante o evento, cada discente teve uma função estabelecida previamente, seguindo o roteiro da roda de conversa.

Quadro 1 - Roteiro da Roda de Conversa

\begin{tabular}{|c|}
\hline $\begin{array}{c}\text { 19h Início / Boas-vindas } \\
\text { Apresentar o tema } \\
\text { Atividade do curso CST Gestão de Turismo / Extensão / Apresentar os } \\
\text { convidados }\end{array}$ \\
\hline 19:05 Apresentação individual dos convidados \\
\hline $\begin{array}{l}\text { 19:10 Questão central: De que maneira a atividade turística exercida por } \\
\text { vocês contribui para a preservação e sustentabilidade do turismo em } \\
\text { Florianópolis? }\end{array}$ \\
\hline 20h Perguntas \\
\hline
\end{tabular}


20:15 Lista das ações consideradas sustentáveis e de preservação / Elaboração da cartilha

20:30 Despedidas e agradecimentos

Fonte: Elaborado pelas autoras

A Roda de Conversa contou com a participação de 65 inscritos. Do total de participantes, $26,2 \%$ foi público da comunidade externa que se interessou pelo tema, recebeu a divulgação da atividade, se inscreveu e compareceu ao encontro. Os demais participantes foram discentes do IFSC (54,4\%); docente do IFSC $(9,2 \%)$; discentes de outra instituição $(6,2 \%)$ e docentes de outra instituição $(3,1 \%)$.

Os convidados Guias de Turismo e Condutores Ambientais realizaram uma apresentação individual e depois contemplaram em suas falas como a atividade turística exercida por eles contribui para a preservação e a sustentabilidade turística em Florianópolis, temática central da roda de conversa. As falas convergiram para condutas relacionadas ao estudo e prática da capacidade de carga dos ambientes, redução do impacto e da produção de resíduos, preservação e valorização ambiental e do patrimônio cultural material e imaterial, como o caso da Fortaleza de São José da Ponta Grossa e das rendeiras que produzem a renda de bilro. Além disso, os convidados concordavam com a ideia de uma atividade turística que promova um convívio harmônico entre o turista e a comunidade receptora. Como ação empreendedora destacada nas falas dos participantes, registrou-se a busca de parcerias com artistas locais e demais profissionais da área do turismo.

A comunidade externa participou ativamente questionando sobre como agir para promover ações conjuntas, o papel das instituições e iniciativas que promovam o turismo responsável em Florianópolis, além de contestarem o perfil de visitantes com pouco conhecimento sobre a conduta adequada para esse tipo de prática turística, valorizando assim, o profissional qualificado para essa atuação.

Como um produto dessa atividade, os discentes extensionistas elaboraram uma cartilha com as principais ações mencionadas pelos convidados que contribuem para uma atividade turística sustentável e que preserve o meio ambiente, assim como a cultura local. Posteriormente, essa cartilha foi divulgada pelos mesmos meios digitais que o evento foi promovido: por e-mail, pelas redes socias e por aplicativo de mensagens. Além disso, a cartilha encontra-se disponível no perfil do curso na rede social Instagram (@gestaoturismo.ifsc). Esse retorno foi uma forma de devolver à comunidade um produto da ação extensionista. 
Figura 2 - Cartilha de ações sustentáveis e de preservação

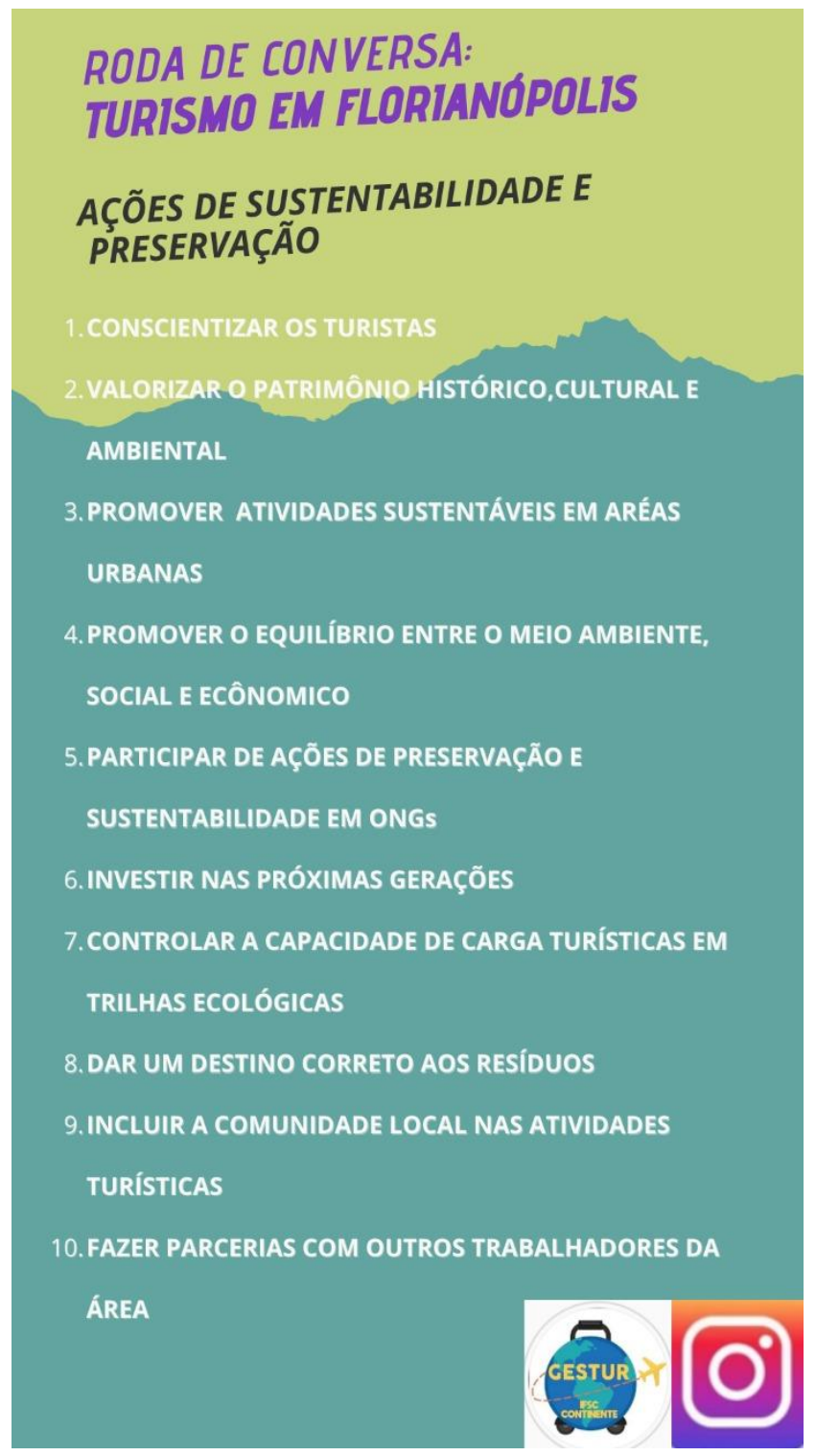

Fonte: Elaborado pela equipe organizadora

Com isso, acredita-se que o objetivo da atividade proposta tenha sido alcançado, pois, foi promovida uma roda de conversa que versou sobre as atividades turísticas sustentáveis que preservem a natureza e a cultura local de Florianópolis, gerando conhecimento acerca do tema e estabelecendo um diálogo com a comunidade participante do evento.

Tendo alcançado o objetivo maior, presume-se que, contemplamos também os objetivos específicos, visto que conhecemos profissionais que promovem atividades turísticas relacionadas à preservação e a sustentabilidade, debatemos as ações promovidas por atividades turísticas relacionadas à preservação e a sustentabilidade, 
divulgamos tanto pelo debate quanto pelo produto final da roda de conversa as ações promovidas por atividades turísticas relacionadas à preservação e a sustentabilidade e conscientizamos a comunidade, dentro de nossas limitações, a respeito das ações promovidas por atividades turísticas relacionadas à preservação e a sustentabilidade.

A experiência da equipe com a participação no Curso "O fazer extensionista", PROEX- IFSC, foi a concretização do aprendizado e do conhecimento acerca da extensão. Essa experiência consolidou a importância do papel da comunidade acadêmica em propor a integração dos discentes, docentes e comunidade externa.

Os convidados, vistos também como público externo, participaram da concepção da atividade auxiliando os estudantes protagonistas da ação na organização da atividade temática, trazendo a interdisciplinaridade permeada pelos principais temas apresentados: turismo, meio ambiente, sustentabilidade, preservação e trabalho.

Os principais desafios da atividade de extensão realizada voltaram-se à organização e logística pessoal e profissional de cada membro da equipe visto que as atividades tiveram prazos curtos para serem realizadas diante da responsabilidade e densidade do conteúdo e responsabilidade da ação que foi elaborada. Mas, como foi mencionado, acredita-se que o objetivo foi alcançado.

Pela experiência com essa vivência e aprendizado, percebeu-se o quanto a comunidade acadêmica tem muito para contribuir, principalmente com projetos que visem compartilhar como o conhecimento acadêmico com a comunidade pode exercer pequenas mudanças.

Em relação ao perfil e atividade profissional, com a abordagem do tema foi possível refletir o quanto Guias de Turismo e Condutores Ambientais são elos importantes e responsáveis entre o turista e a comunidade por meio de falas conscientes de seu papel como profissionais na atividade turística.

Acredita-se que a elaboração da cartilha com as considerações da discussão ocorrida na atividade realizada é uma possibilidade de sensibilização e divulgação dos resultados aos participantes e interessados com o tema da sustentabilidade e preservação em ações da atividade turística.

Como encaminhamentos, já consta nos planejamentos docentes a realização de novas rodas de conversa temáticas com outros grupos de profissionais, compartilhando experiências, promovendo novas interações, gerando mais conhecimento e produtos para a comunidade externa e interna, promovendo a extensão. 


\section{REFERÊNCIAS}

BURGOS, Andrés; MERTENS, Frédéric. Os desafios do turismo no contexto da sustentabilidade: as contribuições do turismo de base comunitária. PASOS- Revista de Turismo y Patrimonio Cultural, Santa Cruz de Tenerife, v. 13, n. 1, p. 57-71, 2015.

Organização Mundial do Turismo. Turismo por los ODS. Disponível em:

https://www.unwto.org/es/tourismo-por-los-ods. Acesso em: 14 dez. 2020.

Os autores declaram participação na autoria conforme a Taxonomia CRediT da Casari (vide https://casrai.org/)

\begin{tabular}{|c|c|c|c|c|c|c|}
\hline Conceituação & Metodologia & Software & Validação & Análise formal & Investigação & Recursos \\
\hline$[1] /[2]$ & {$[2]$} & & & {$[1]$} & {$[1] /[2]$} & \\
\hline Curadoria & Primeira redação & Revisão/edição & Visualização & Supervisão & Admin. projeto & Financiamento \\
\hline & {$[1] /[2]$} & {$[1] /[2]$} & & & & \\
\hline
\end{tabular}

